\title{
Corrigendum \\ Consumer factors associated with purchasing local versus global value chain foods - CORRIGENDUM
}

Svetlana Bogomolova, Adam Loch, Larry Lockshin and Jon Buckley

doi: 10.1017/S1742170516000375. Published online by Cambridge University Press, 3 November 2016

In the recent publication mentioned above, the authors would like to apologise for incorrectly attributing the references in table 1 . The correct table 1 is detailed below:

\section{Reference}

Bogomolova, S., Loch, A., Lockshin, L. and Buckley, J. 2016. Consumer factors associated with purchasing local versus global value chain foods. Renewable Agriculture and Food Systems 1-14. doi: 10.1017/S1742170516000375. 
Table 1. Summary of relevant studies on demographic characteristics and propensity to buy local foods.

\begin{tabular}{|c|c|c|c|c|c|c|c|c|c|c|}
\hline Authors & Location & Categories/outlets & Gender & Age & SES/income & Education & Location & Hous. size & Ethnicity & Outcome measure \\
\hline $\begin{array}{l}\text { (Memery et al., } \\
\text { 2015) }\end{array}$ & England, UK & $\begin{array}{l}\text { Local food at } \\
\text { farmers markets }\end{array}$ & female & $55+$ & ns & ns & ns & & & $\begin{array}{l}\text { Self-reported past purchase } \\
\text { of local products and } \\
\text { future intentions }\end{array}$ \\
\hline $\begin{array}{l}\text { (Racine et al., } \\
\text { 2013) }\end{array}$ & $\begin{array}{l}\text { North Carolina, } \\
\text { US }\end{array}$ & $\begin{array}{l}\text { Local food at } \\
\text { farmers markets }\end{array}$ & & & lower & & rural & $\begin{array}{c}\text { Hous. with } \\
\text { children }\end{array}$ & white & $\begin{array}{l}\text { Self-reported past purchase } \\
\text { of local products }\end{array}$ \\
\hline $\begin{array}{l}\text { (Gracia et al., } \\
\text { 2012) }\end{array}$ & Aragon, Spain & 1 category: Lamb & female & & & & & & & $\begin{array}{l}\text { Actual bids and eventual } \\
\text { purchases }\end{array}$ \\
\hline $\begin{array}{l}\text { (Cranfield et al., } \\
\text { 2012) }\end{array}$ & $\begin{array}{l}\text { City of Guelph, } \\
\text { Ontario, } \\
\text { Canada }\end{array}$ & Local foods & female & mixed & ns & higher & & mixed & & $\begin{array}{l}\text { Claimed likelihood to } \\
\text { purchase }\end{array}$ \\
\hline $\begin{array}{l}\text { (Conner et al., } \\
\text { 2010) }\end{array}$ & Michigan, US & $\begin{array}{l}\text { Locally grown } \\
\text { foods at farmers } \\
\text { markets }\end{array}$ & ns & ns & $\begin{array}{l}\text { part-time } \\
\text { employment }\end{array}$ & ns & & $\mathrm{N}$ of adults & ns & $\begin{array}{l}\text { Self-reported past purchases } \\
\text { of local products }\end{array}$ \\
\hline $\begin{array}{l}\text { (Conner et al., } \\
\text { 2010) }\end{array}$ & Michigan, US & $\begin{array}{c}\text { Farmers market } \\
\text { participation }\end{array}$ & & & $\begin{array}{l}\text { (-) working } \\
\text { part-time }\end{array}$ & & & $\begin{array}{l}\text { single person } \\
\text { hous. }\end{array}$ & white & $\begin{array}{l}\text { Self-reported past market } \\
\text { attendance }\end{array}$ \\
\hline (Zepeda, 2009) & US & $\begin{array}{l}\text { Local produce at } \\
\text { farmers markets }\end{array}$ & female & ns & ns & ns & ns & more adults & ns & $\begin{array}{l}\text { Self-reported past patronage } \\
\text { of farmers markets }\end{array}$ \\
\hline $\begin{array}{l}\text { (Brown et al., } \\
\text { 2009) }\end{array}$ & $\begin{array}{l}\text { Montpellier, } \\
\text { France, } \\
\text { Nottingham, } \\
\text { UK }\end{array}$ & $\begin{array}{l}\text { Commercial fruit } \\
\text { and vegetable } \\
\text { box schemes }\end{array}$ & & older & $\begin{array}{l}\text { have profes- } \\
\text { sional } \\
\text { occupation }\end{array}$ & & & & & $\begin{array}{l}\text { Description of participants } \\
\text { in the box scheme against } \\
\text { census }\end{array}$ \\
\hline $\begin{array}{l}\text { (Carpio and } \\
\text { Isengildina- } \\
\text { Massa, 2009) }\end{array}$ & $\begin{array}{l}\text { South Carolina, } \\
\text { US }\end{array}$ & $\begin{array}{l}\text { Local produce and } \\
\text { animal products }\end{array}$ & female & older & higher & & $\begin{array}{c}\text { work in } \\
\text { agric }\end{array}$ & $\mathrm{ns}$ & & $\begin{array}{l}\text { Claimed willingness to pay } \\
\text { extra for local produce } \\
\text { and (separately) for local } \\
\text { animal products }\end{array}$ \\
\hline $\begin{array}{l}\text { (Robinson- } \\
\text { O'Brien et al., } \\
\text { 2009) }\end{array}$ & Minnesota, US & $\begin{array}{l}\text { Eating local, } \\
\text { organically, non- } \\
\text { GM and non- } \\
\text { processed }\end{array}$ & female & ns & low-mid & & & & $\begin{array}{l}\text { non-white } \\
\text { (hispanic } \\
\text { and asian) }\end{array}$ & $\begin{array}{l}\text { Attitudes towards four } \\
\text { alternative food practices: } \\
\text { a) organic, b) not pro- } \\
\text { cessed, c) locally grown, } \\
\text { and d) not genetically } \\
\text { engineered }\end{array}$ \\
\hline $\begin{array}{l}\text { (Zepeda and } \mathrm{Li} \text {, } \\
\text { 2006) }\end{array}$ & US & $\begin{array}{l}\text { Famers markets, } \\
\text { farmer direct }\end{array}$ & ns & ns & low/mid & ns & ns & $>1$ adult & ns & $\begin{array}{l}\text { Self-reported past purchases } \\
\text { from farmers markets or } \\
\text { directly from farmers }\end{array}$ \\
\hline $\begin{array}{l}\text { (Onianwa et al., } \\
\text { 2005) }\end{array}$ & Alabama, US & farmers markets & ns & ns & ns & higher & ns & $\begin{array}{l}\text { Hous. with } \\
\text { children } \\
\text { with } \\
\text { higher } \\
\text { income }\end{array}$ & ns & $\begin{array}{l}\text { Self-reported past patronage } \\
\text { of farmers markets }\end{array}$ \\
\hline
\end{tabular}


Table 1. (Cont.)

\begin{tabular}{|c|c|c|c|c|c|c|c|c|c|c|}
\hline Authors & Location & Categories/outlets & Gender & Age & SES/income & Education & Location & Hous. size & Ethnicity & Outcome measure \\
\hline (Brown, 2003) & Tennessee, US & $\begin{array}{l}\text { Fruits and vegeta- } \\
\text { bles, food labeled } \\
\text { organic }\end{array}$ & & & higher & higher & farm & & & $\begin{array}{l}\text { Self-reported past purchases } \\
\text { of organic foods and fresh } \\
\text { fruits and vegetables }\end{array}$ \\
\hline $\begin{array}{l}\text { (Jekanowski, } \\
\text { 2000) }\end{array}$ & Indiana, US & $\begin{array}{l}\text { Locally produced } \\
\text { agricultural } \\
\text { products }\end{array}$ & female & & higher & lower & $\begin{array}{r}\text { Longer } \\
\text { rural }\end{array}$ & $\mathrm{ns}$ & & $\begin{array}{l}\text { Self-reported future inten- } \\
\text { tions to purchase local } \\
\text { products }\end{array}$ \\
\hline $\begin{array}{l}\text { (Eastwood et al., } \\
\text { 1999) }\end{array}$ & Tennessee, US & $\begin{array}{l}\text { Farmers markets } \\
\text { and other } \\
\text { farmer-outlets }\end{array}$ & female & older & higher & higher & & & white & $\begin{array}{l}\text { Description of patrons of } \\
\text { farmers markets and other } \\
\text { farmer-outlets against } \\
\text { census }\end{array}$ \\
\hline $\begin{array}{l}\text { Summary of past } \\
\text { studies }\end{array}$ & $\begin{array}{l}\text { 12/15 studies } \\
\text { come from US } \\
\text { or Canada }\end{array}$ & $\begin{array}{l}\text { All studies focus on } \\
\text { farmers markets } \\
\text { and farmer direct } \\
\text { delivery }\end{array}$ & female & older & mixed & higher & rural & mixed & mixed & $\begin{array}{l}\text { All but } 1 \text { study use self- } \\
\text { reported or claimed past or } \\
\text { future behaviors }\end{array}$ \\
\hline
\end{tabular}

